ARTICLE

Received 14 Feb 2015 | Accepted 22 Jun 2015 | Published 29 Jul 2015 | Updated 28 Aug 2015

DOI: $10.1038 /$ ncomms 8879

\title{
GABA signalling modulates plant growth by directly regulating the activity of plant-specific anion transporters
}

Sunita A. Ramesh ${ }^{1, \star}$, Stephen D. Tyerman ${ }^{1, \star}$, Bo X $\mathbf{u}^{1}$, Jayakumar Bose ${ }^{1,2}$, Satwinder Kaur ${ }^{1}$, Vanessa Conn ${ }^{1}$, Patricia Domingos ${ }^{3,4}$, Sana Ullah¹, Stefanie Wege ${ }^{1}$, Sergey Shabala ${ }^{2}$, José A. Feijó ${ }^{3,4}$, Peter R. Ryan ${ }^{5} \&$ Matthew Gilliham ${ }^{1}$

The non-protein amino acid, gamma-aminobutyric acid (GABA) rapidly accumulates in plant tissues in response to biotic and abiotic stress, and regulates plant growth. Until now it was not known whether GABA exerts its effects in plants through the regulation of carbon metabolism or via an unidentified signalling pathway. Here, we demonstrate that anion flux through plant aluminium-activated malate transporter (ALMT) proteins is activated by anions and negatively regulated by GABA. Site-directed mutagenesis of selected amino acids within ALMT proteins abolishes GABA efficacy but does not alter other transport properties. GABA modulation of ALMT activity results in altered root growth and altered root tolerance to alkaline $\mathrm{pH}$, acid $\mathrm{pH}$ and aluminium ions. We propose that GABA exerts its multiple physiological effects in plants via ALMT, including the regulation of pollen tube and root growth, and that GABA can finally be considered a legitimate signalling molecule in both the plant and animal kingdoms.

\footnotetext{
${ }^{1}$ Australian Research Council Centre of Excellence in Plant Energy Biology, Department of Plant Science, Waite Research Institute, School of Agriculture, Food and Wine, University of Adelaide, PMB1, Glen Osmond, South Australia 5064, Australia. ${ }^{2}$ School of Land and Food, University of Tasmania, Private Bag 54, Hobart, Tasmania 7001, Australia. ${ }^{3}$ Gulbenkian Institute of Science, Oeiras P-2780-156, Portugal. ${ }^{4}$ Department of Cell Biology and Molecular Genetics, University of Maryland, College Park, Maryland 20742-5815, USA. ${ }^{5}$ CSIRO Plant Industry, GPO Box 1600, Canberra, Australian Capital Territory 2601, Australia. *These authors contributed equally to this work. Correspondence and requests for materials should be addressed to M.G. (email: matthew.gilliham@adelaide.edu.au).
} 
R apid increases in gamma-aminobutyric acid (GABA) concentration occur in plants in response to extreme temperatures, dehydration, salinity, oxygen stress, mechanical damage, acidosis, virus infection and defence against herbivory ${ }^{1,2}$. Elevated GABA concentrations reduce root growth $^{3}$, while GABA gradients are required in the female reproductive tissues to guide pollen tubes to the ovary to ensure successful fertilization ${ }^{4}$. This has led to speculation that GABA signalling occurs in plants, as it does in mammals ${ }^{1,2,5}$. However, as no molecular components for GABA signalling in plants have been identified ${ }^{1,2}$, and there are no plant homologues of mammalian GABA receptors ${ }^{1,2,5}$, it has remained unclear whether changes in GABA concentration constitute a metabolic response or an adaptive signal ${ }^{1,2,6}$.

While examining the effect of combining stresses that can modulate plant growth individually ${ }^{1-3}$, we observed an unexpected interplay between acidosis, trivalent aluminium ions $\left(\mathrm{Al}^{3+}\right)$ and GABA accumulation. This finding has led us to the identification of aluminium-activated malate transporters (ALMT) as key transducers of GABA signalling in plants. ALMT form a large multigenic anion channel family exclusive to plants with multiple physiological roles and discrete expression patterns ${ }^{7}$. We demonstrate the impact of GABA regulation of ALMT activity in wheat roots during $\mathrm{pH}$ and aluminium stress. More broadly, our findings reveal that GABA-mediated regulation of ALMT proteins underlies a novel signalling pathway that has the potential to translate changes in the concentration of this plant stress metabolite into physiological outputs throughout the plant.

\section{Results}

GABA regulates malate flux from wheat roots. Acidosis is one of the multitude of stresses that increases GABA concentration in plant cells ${ }^{2}$. Trivalent aluminium ions $\left(\mathrm{Al}^{3+}\right)$ are a frequent cooccurring stress in acid soils ${ }^{8}$. Using near-isogenic lines (NILs) of bread wheat (Triticum aestivum, Ta) that differ in their $\mathrm{Al}^{3+}$ tolerance, we found that GABA concentrations under acidic conditions were significantly higher in roots of the $\mathrm{Al}^{3+}$-tolerant NIL ET8 compared with those of ES8, the $\mathrm{Al}^{3+}$-sensitive NIL. However, simultaneous application of $\mathrm{Al}^{3+}$ and $\mathrm{pH} 4.5$ reduced the GABA concentration in both lines to equivalent levels (Fig. 1a). ET8 and ES8 differ in their abundance of the malate-permeable transporter TaALMT1 in the plasma membrane of root apical cells $^{8,9}$. In ET8, where TaALMT1 is abundant, $\mathrm{Al}^{3+}$ stimulates sufficient malate efflux at the root tip to chelate $\mathrm{Al}^{3+}$ in acid soils and prevent $\mathrm{Al}^{3+}$-induced cellular damage; this allows root growth to continue and confers $\mathrm{Al}^{3+}$ tolerance ${ }^{8,9}$. Therefore, we tested whether exogenously applied GABA had a differential effect on these lines and their tolerance to $\mathrm{Al}^{3+}$. At low $\mathrm{pH}$, application of GABA to ET8 roots significantly reduced both $\mathrm{Al}^{3}+$-activated malate efflux and root growth in the presence of $\mathrm{Al}^{3+}$, whereas GABA had no significant effect on these parameters in ES8 (Fig. 1b,c). As such, we could phenocopy the root growth sensitivity of ES8 to $\mathrm{Al}^{3+}$ in ET8 by simultaneously applying GABA at pH 4.5 (Fig. 1c). Overall, our data showed a significant correlation between root growth and malate efflux in the presence of $\mathrm{Al}^{3+}$ at $\mathrm{pH} 4.5$ (Fig. 1c) ${ }^{8,9}$. We also found that muscimol-a potent analogue of GABA and specific agonist of mammalian $\mathrm{GABA}_{\mathrm{A}}$ receptors ${ }^{5}$ - selectively reduced malate efflux and root growth of ET8 (not ES8) (Fig. 1c). This effect of muscimol could be attenuated by bicuculline, a competitive antagonist of GABA binding to mammalian $\mathrm{GABA}_{\mathrm{A}}$ receptors $^{5}$ (Supplementary Fig. 1).

GABA regulates activity of TaALMT1. To test whether muscimol was acting via TaALMT1, we used transgenic barley overexpressing TaALMT1 (ref. 10). Barley is among the most $\mathrm{Al}^{3+}$-sensitive cereals and naturally exhibits a very low level of $\mathrm{Al}^{3+}$-stimulated malate efflux compared with $\mathrm{Al}^{3+}$-tolerant wheat ${ }^{10}$. However, both $\mathrm{Al}^{3+}$-stimulated malate efflux and $\mathrm{Al}^{3+}$-tolerance (that is, root growth in the presence of $\mathrm{Al}^{3+}$ ) was increased in barley overexpressing TaALMT1 when compared with wild-type (WT) barley or null transgenic lines ${ }^{10}$ (Fig. 2a). Both $\mathrm{Al}^{3+}$-dependent malate efflux and root growth of barley overexpressing TaALMT1 was reduced by muscimol, whereas muscimol had no effect on either component in the null lines or WT barley (Fig. 2a). As both muscimol and bicuculline are used as diagnostics for the activity of mammalian $\mathrm{GABA}_{\mathrm{A}}$ receptors ${ }^{5}$, which are anion channels that are gated by GABA, we examined the effects of these compounds on the anion transport activity of ALMT protein in heterologous expression systems a

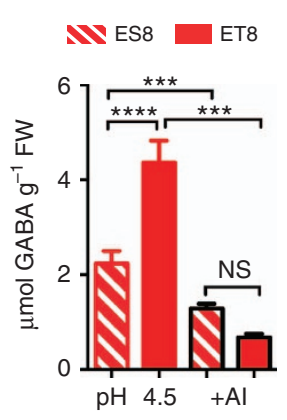

b

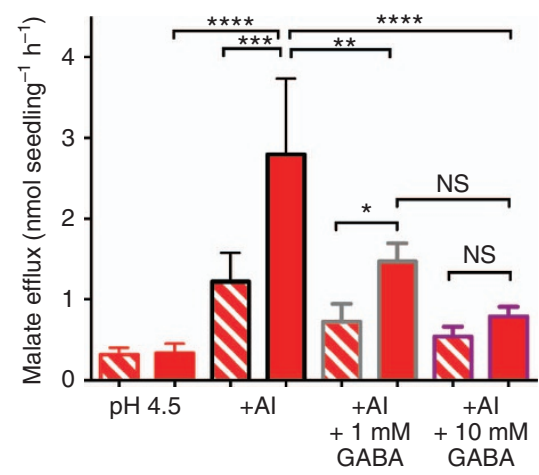

C

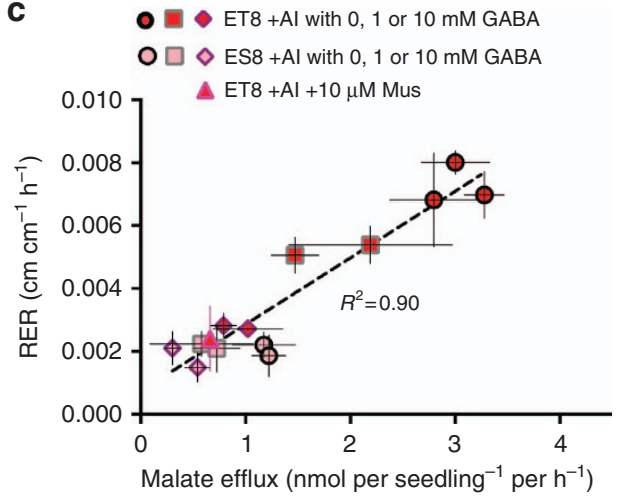

Figure 1 | GABA regulates the magnitude of $\mathbf{A} \mathbf{I}^{\mathbf{3}}+$-induced malate flux and the extent of wheat root $\mathbf{A} \mathbf{l}^{\mathbf{3}}+$ tolerance. Hydroponically grown seedlings of near-isogenic wheat lines ET8 ( $\mathrm{Il}^{3+}$ tolerant) and $\mathrm{ES} 8\left(\mathrm{Al}^{3+} \text { sensitive }\right)^{8}$ were used in all experiments, roots were bathed in basal nutrient solution at $\mathrm{pH} 4.5 \pm 100 \mu \mathrm{M} \mathrm{Al}^{3+}(+\mathrm{Al}) \pm 1$ or $10 \mathrm{mM} \mathrm{GABA}$, or $10 \mu \mathrm{M}$ muscimol (Mus) for $22 \mathrm{~h}$. (a) The concentration of GABA in ET8 and ES8 wheat roots is decreased in response to $\mathrm{Al}$ treatment. (b) Malate efflux from wheat roots is increased by $\mathrm{Al}$ and decreased in response to $\mathrm{Al}$ and GABA treatment in ET8, not ES8 wheat. (c) Root malate efflux and root relative elongation rate (RER $=\left(\log _{\mathrm{e}}\right.$ (length at $\left.22 \mathrm{~h}\right)-\log _{\mathrm{e}}($ length at $\left.\left.0 \mathrm{~h})\right) / 22 \mathrm{~h}\right)$ is positively correlated in ET8 in the presence of Al. Both parameters are negatively regulated by GABA and Mus, which phenocopies the response of ES8 to Al. ${ }^{*},{ }^{\star \star}$, ${ }^{\star \star \star}$ and ${ }^{\star \star \star \star \star}$ indicate significant differences between genotypes at $P<0.05,0.01,0.001$ and 0.0001 , respectively, using a one-way ANOVA; NS, not significantly different. The significance comparisons between some groups have been omitted for clarity. All data $n=5$ biological replicates, all error bars are \pm s.e.m. All experiments were repeated at least three times. 
a

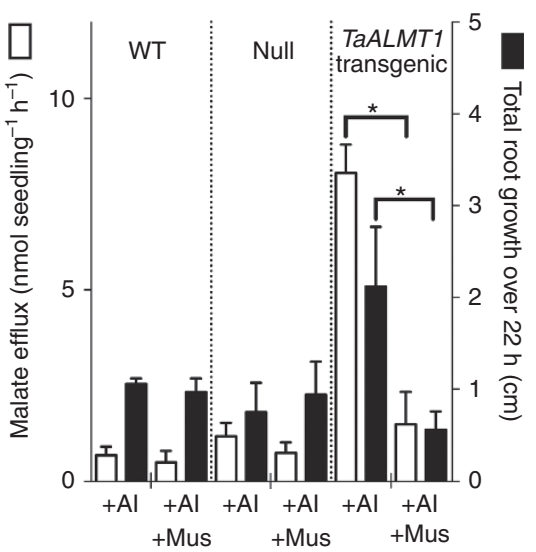

b
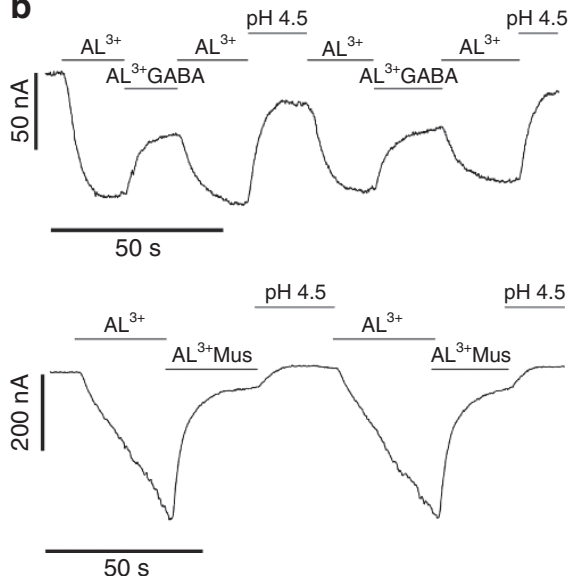

C

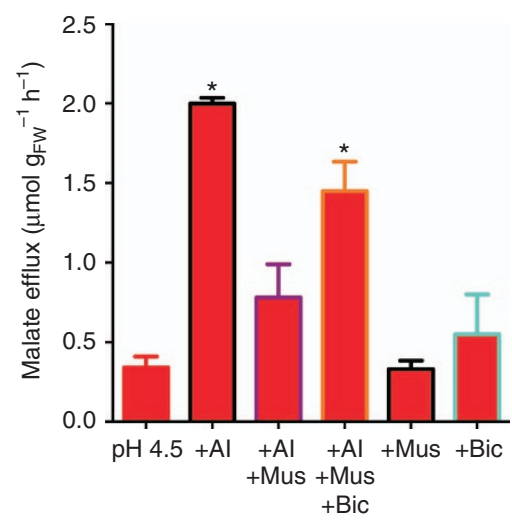

Figure 2 | GABA regulates Al ${ }^{\mathbf{3}+}$-activated malate efflux through TaALMT1. (a) TaALMT1 expression in barley ${ }^{10}$ increases malate efflux and root growth of barley in the presence of $100 \mu \mathrm{m} \mathrm{Al}{ }^{3+}$ at $\mathrm{pH} 4.5$, over $22 \mathrm{~h}$, but this is negatively regulated by $10 \mu \mathrm{M}$ muscimol (Mus). (b) Representative current traces from TaALMT1-injected X. laevis oocytes voltage-clamped at $-120 \mathrm{mV}$ challenged with $100 \mu \mathrm{m} \mathrm{Al} \mathrm{I}^{3+} \pm 100 \mu \mathrm{m}$ GABA or $10 \mu \mathrm{M}$ muscimol (Mus) at $\mathrm{pH}$ 4.5. (c) Malate efflux from TaALMT1-expressing BY2 cells ${ }^{11}$ in standard BY2 solution at pH $4.5 \pm 100 \mu \mathrm{m} \mathrm{Al} \mathrm{I}^{3+} \pm 10 \mu \mathrm{m}$ Mus $\pm 100 \mu \mathrm{m}$ bicuculline (Bic). For controls for $\mathbf{b}$ and $\mathbf{c}$, see Supplementary Fig. 2. ${ }^{*}$ indicates significant differences between genotypes at $P<0.05$ using a two-tailed $t$-test (a) or one-way analysis of variance (c). Full-TaALMT1 sequence identifier (DQ072260). All data $n=5$ biological replicates (except $\mathbf{b}$, which are representative traces from $n=5$ ). All error bars are \pm s.e.m. Transgenic barley experiments were repeated twice, Xenopus oocyte experiments were repeated with at least three different frogs and BY2 tobacco cell experiments were repeated thrice.

using two-electrode voltage-clamp electrophysiology and flux analysis. Both GABA and muscimol negatively regulated $\mathrm{Al}^{3+}$. induced TaALMT1-mediated currents in Xenopus laevis oocytes (Fig. 2b; Supplementary Fig. 2a) and TaALMT1-mediated malate efflux in transgenic Tobacco BY2 cells ${ }^{8,11}$ (Fig. 2c). Furthermore, bicuculline attenuated the effect of muscimol on $\mathrm{Al}^{3+}$-induced fluxes in BY2 cells (Fig. 2c; Supplementary Fig. 2c). We examined the possibility that endocytosis of TaALMT1 contributed to the reduction in malate efflux following GABA treatment, but found no effect of the endocytosis inhibitor Brefeldin $\mathrm{A}^{12}$ on $\mathrm{Al}^{3+}$-activated malate efflux or the inhibition by muscimol (Supplementary Fig. 3).

During the study of TaALMT1 activity we were surprised to find that at alkaline $\mathrm{pH}$, in the absence of $\mathrm{Al}^{3+}$, TaALMT1 could be activated by malate (Fig. 3) or a variety of other anions (Supplementary Fig. 4). Malate-induced malate flux through TaALMT1 was much greater at alkaline $\mathrm{pH}$ in both tobacco BY2 cells ${ }^{11}$ (Fig. 3a) and X. laevis oocytes expressing TaALMT1 (Supplementary Fig. 4a), with a $K_{\mathrm{m}}$ for malate activation of $1.1 \mathrm{mM}$ (Supplementary Fig. 4c). Anion-activated malate efflux was negatively regulated by GABA and muscimol (Fig. 3b; Fig. 4; Supplementary Fig. 5), and this effect was attenuated by bicuculline (Fig. 3b; Fig. 4a; Supplementary Fig. 6). The affinity for GABA and muscimol regulation at $\mathrm{pH} 7.5$ was in the low micromolar range (half-maximal effective concentration $=3.2 \mu \mathrm{M} \quad(\mathrm{GABA})$ and $5.5 \mu \mathrm{M} \quad$ (muscimol)) (Fig. $4 \mathrm{~b}-\mathrm{d}$ ).

Elevated GABA concentrations in plant tissues at low $\mathrm{pH}$ (as shown in Fig. 1a) has been proposed to regulate cytosolic $\mathrm{pH}$ through the activity of $\mathrm{Ca}^{2+} / \mathrm{CAM}$-stimulated glutamate decarboxylase, which consumes protons by converting glutamate to $\mathrm{GABA}^{1}$; our observations suggest that GABA is playing an additional role. At low $\mathrm{pH}$, in the absence of $\mathrm{Al}^{3+}, \mathrm{GABA}$ and muscimol had no effect on malate efflux, whereas it was significantly increased by bicuculline (Fig. $3 \mathrm{~b}$ ). This suggests that bicuculline can partially override the inhibition that high concentrations of endogenous GABA may have on TaALMT1 activity and malate efflux at acidic $\mathrm{pH}$ in the absence of $\mathrm{Al}^{3+}$. As such, bicuculline appears to act as a competitive antagonist to
GABA action for TaALMT1, as it does for mammalian $\mathrm{GABA}_{\mathrm{A}}$ receptors. At alkaline $\mathrm{pH}$, endogenous GABA concentration decreased when anions were added externally (Supplementary Fig. 7); this is a condition where greater malate efflux occurs through TaALMT1 in heterologous expression systems (Fig. 3; Supplementary Figs 4 and 5). At alkaline $\mathrm{pH}$, when significant anion activation of TaALMT1 would ordinarily occur, GABA and muscimol were effective in decreasing malate efflux (Figs $3 \mathrm{~b}$ and 4). While the mechanism that brings about a decrease in GABA concentration at alkaline $\mathrm{pH}$ is unclear, the fact that it is low in such conditions may allow for a greater efflux of malate to occur from the roots when in an alkaline environment.

GABA regulation of TaALMT1 alters plant membrane potential. To test the physiological significance of anion activation of TaALMT1 at alkaline pH, we again used wheat NILs ET8 and ES8. We observed substantial malate efflux from ET8 roots in the presence of an external activating anion, but not from roots of ES8 (Fig. 5a). This alkaline $\mathrm{pH}$-dependent stimulation of malate efflux was inhibited by muscimol (Fig. 5a), and this reduction in malate efflux was again coincident with a reduction of root growth (Fig. 5b). Activation of anion channels will tend to depolarize the plasma membrane potential difference $(\mathrm{PD})^{13}$, so we examined the PD responses of epidermal cells in the root apex of ET8 and ES8 in both alkaline and acid conditions. Under alkaline conditions, addition of external anions depolarized the PD of ET8 to a greater extent than ES8 (Fig. 5c), and concurrent addition of muscimol with anions abolished this difference between lines (Fig. 5d); muscimol application to roots in the absence of channel activation did not significantly affect membrane potential (Supplementary Fig. 8a). The same trends were apparent at $\mathrm{pH} 4.5$ following $\mathrm{Al}^{3+}$ treatment-ET8 were more depolarized than ES8, and muscimol abolished the differences between the genotypes (Supplementary Fig. $8 \mathrm{~b}-\mathrm{d}$ ). This confirms that wheat roots sense muscimol and anions rapidly and in a TaALMT1-dependent manner, as could be predicted by its effects on TaALMT1 in heterologous expression systems (Figs $2 \mathrm{~b}$ and $4 \mathrm{a}$ ). Modulation of PD is known to result in many downstream responses in plants from changes in cell turgor, 

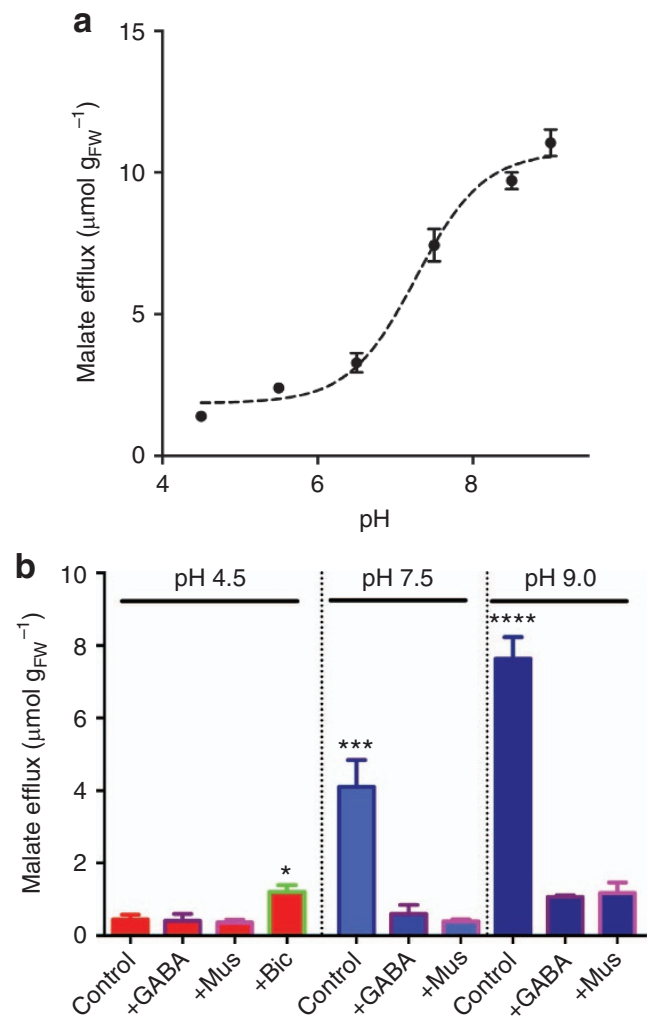

Figure 3 | TaALMT1-mediated fluxes are activated by external anions at alkaline $\mathbf{p H}$ and regulated by GABA, muscimol and bicuculline. (a) Malate efflux from TaALMT1-expressing BY2 cells ${ }^{11}$ in standard BY2 solution $+10 \mathrm{mM} \mathrm{SO}_{4}^{2-}$ increases with increasing $\mathrm{pH}$ over $22 \mathrm{~h}$. (b) Malate efflux from TaALMT1-expressing BY2 cells ${ }^{11}$ in the absence of $\mathrm{Al}^{3+}+10 \mathrm{mM}$ $\mathrm{SO}_{4}^{2-}$ is negatively regulated by $100 \mu \mathrm{m} \mathrm{GABA}$ or $10 \mu \mathrm{m}$ muscimol (Mus) at alkaline $\mathrm{pH}$, and increased by $100 \mu \mathrm{m}$ bicuculline (Bic) at $\mathrm{pH}$ 4.5. ${ }^{\star}$, $\star \star \star *$ and ${ }^{\star \star \star \star}$ indicate significant differences between genotypes at $P<0.05$, 0.001 and 0.0001 , respectively, using a one-way analysis of variance (b). All data $n=3$ biological replicates, all error bars are \pm s.e.m. All experiments were repeated three times.

growth and in gene expression ${ }^{13}$; this suggests that ALMT are prime candidates for transducing GABA signals in plants.

GABA regulation is a conserved feature of ALMT proteins. TaALMT1 was the founding member of the ALMT family ${ }^{8}$, which consists of a large number of anion channel encoding genes present in all plant species-Arabidopsis has 14, grapevine 13, soybean 33 and there are 9 in rice. Different family members have been proposed to have specific physiological roles ${ }^{7}$. Despite their name-a legacy of their founding member-many characterized ALMT are not activated by $\mathrm{Al}^{3+}$ nor have any role in $\mathrm{Al}^{3+}$ tolerance ${ }^{7}$, and they can be activated by millimolar concentrations of anions on the cis side of the protein when permeant anions are present on the trans side ${ }^{7,13-15}$. Some ALMT are preferentially selective for anions other than malate ${ }^{14}$. By examining eight ALMT from five plant species (Arabidopsis, wheat, barley, rice and grapevine), our results suggest that GABA regulation of anion-activated currents is a general feature of this family (Fig. 6a; Supplementary Fig. 9a).

ALMT proteins contain a motif essential for GABA regulation. As regulation of ALMT activity by GABA occurred in the low micromolar range, we attempted to elucidate what residues were important for this effect by comparing sequences of mammalian GABA receptors ${ }^{5}$ and $\mathrm{ALMT}^{7}$. GABA is a major inhibitory neurotransmitter, which acts as a signal by regulating ion flow across cell membranes via two classes of receptors, the $\mathrm{GABA}_{\mathrm{A}}$ and $\mathrm{GABA}_{\mathrm{B}}{ }^{5}$. $\mathrm{GABA}_{\mathrm{A}}$ receptors consist of multiple subunits that can assemble into a functional homomeric or heteromeric channel ${ }^{5}$. A model of a human $\alpha_{1} \beta_{2} \gamma_{2}$ GABA $_{A}$ receptor was constructed that predicts residues important for binding $\mathrm{GABA}^{16}$; many of these residues were subsequently validated as part of a neurotransmitter-binding pocket when the crystal structure of a human homopentimeric $\beta 3$ subunit $\mathrm{GABA}_{\mathrm{A}}$ receptor was resolved ${ }^{17}$. Here, using $\mathrm{MEME}^{18}$ analysis we discovered a region, 12 amino acids in length, shared between ALMT and the ion channels used to construct the $\alpha_{1} \beta_{2} \gamma_{2}$ GABA $_{A}$ receptor model ${ }^{16}$ (Fig. 6b,c; Supplementary Fig. 10). Sequence analysis suggested that all known ALMT contain this motif and, as is the case for $\mathrm{GABA}_{\mathrm{A}} \alpha$ - and $\beta$-subunits ${ }^{8,16,17}$ or $\mathrm{GABA}_{\mathrm{A}-\rho}$ receptors ${ }^{19-21}$, that the aromatic amino-acid residues phenylalanine $(\mathrm{F})$ or tyrosine $(\mathrm{Y})$ contained within the shared motif may be important for GABA efficacy (Fig. 6c; Supplementary Figs 11 and 12). There is debate about the number of transmembrane-spanning domains within ALMT, and their orientation, particularly with regard to the $\mathrm{C}$ terminus ${ }^{7}$. However, under current convention the motif spanning aminoacid positions $213-224$ in TaALMT1 is predicted to reside near the end of the sixth transmembrane domain, on the external face of the plasma membrane ${ }^{22}$. The rapidity and reversibility of GABA regulation is consistent with GABA interaction occurring from the cell exterior (Figs $2 \mathrm{~b}$ and $4 \mathrm{a}$ ).

To test our predictions about GABA interaction, we performed site-directed mutagenesis on the first and second aromatic residues within this motif in TaALMT1 either in isolation $\left(\mathrm{TaALMT1} 1^{\mathrm{F} 213 \mathrm{C}}\right.$ or TaALMT1 $\left.{ }^{\mathrm{F} 215 \mathrm{C}}\right)$ or in combination (TaALMT1 $^{\mathrm{F} 213 \mathrm{C} / \mathrm{F} 215 \mathrm{C}}$ ), and a $\mathrm{Y}$ to $\mathrm{C}$ conversion of Vitis vinifera ALMT9 (VvALMT9Y237C), which is the first aromatic residue in that motif. All mutant proteins retained strong activation by external anions (Fig. 7a), however, TaALMT1 ${ }^{\mathrm{F} 213 \mathrm{C}}$, TaALMT1 ${ }^{\text {F213C/F215C } \text { and VvALMT9 }}{ }^{\mathrm{Y} 237 \mathrm{C}}$ were not inhibited by $100 \mu \mathrm{M}$ GABA, whereas inward current through TaALMT1 ${ }^{\text {F215C }}$ was reduced by GABA (Fig. 7a). The halfmaximal effective concentration for GABA regulation for TaALMT1 increased from $3.2 \mu \mathrm{M}$ to over $1 \mathrm{mM}$ for TaALMT1 ${ }^{\text {F213C/F215C }}$, and from $5 \mu \mathrm{M}$ in VvALMT9 to $697 \mu \mathrm{M}$ in VvALMT9 ${ }^{\mathrm{Y} 237 \mathrm{C}}$ (Supplementary Fig. 8b). All mutant TaALMT1 also tested positive for $\mathrm{Al}^{3+}$ activation, and only TaALMT1 ${ }^{\mathrm{F} 215 \mathrm{C}}$ retained sensitivity to $10 \mu \mathrm{M}$ muscimol (Fig. $7 \mathrm{a}$ ). We observed a strong physical interaction of a fluorescent muscimol conjugate ${ }^{23}$ with the surface of $X$. laevis oocytes when injected with TaALMT1, but not following TaALMT1 ${ }^{\mathrm{F} 213 \mathrm{C}}$ or water injection (Fig. 7b,c). ALMT activation by anions or $\mathrm{Al}^{3+}$ are processes believed to be dependent upon amino-acid residues identified within the $\mathrm{N}$ - and $\mathrm{C}$ terminus ${ }^{24,25}$; our findings are consistent with the GABA-responsive motif being distinct from these regions. We further investigated the interaction of GABA with ALMT by co-exposing $X$. laevis oocytes injected with TaALMT1 with the fluorescent muscimol conjugate ${ }^{23}$ and GABA. We observed a significant lower fluorescence signal from TaALMT1-injected oocytes co-incubated with the fluorescent muscimol conjugate and GABA compared with those not exposed to GABA; however, the fluorescence was significantly greater from co-incubated oocytes than from waterinjected control oocytes (Fig. 7b,c). These findings suggest that GABA and the fluorescent muscimol conjugate are in direct competition for their association with TaALMT1. The evidence that muscimol and GABA directly associate with TaALMT1 is also strengthened by the in planta observation that the 
a

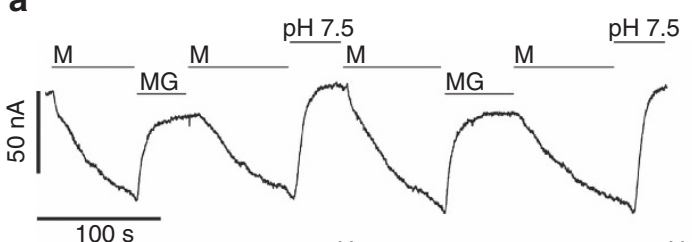

b

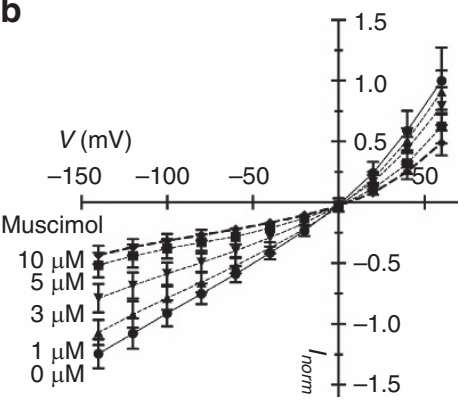

C

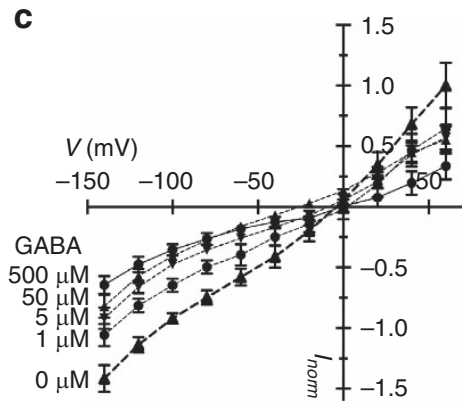

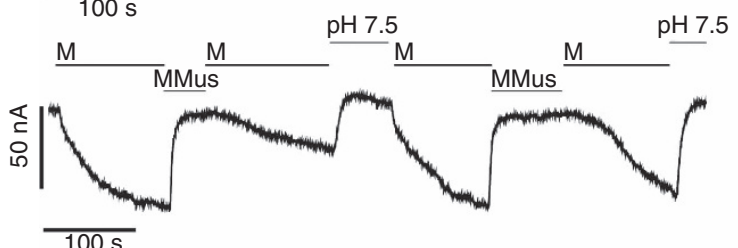

$\mathrm{pH} 7.5$

$100 \mathrm{~s}$

$\mathrm{pH} 7.5 \quad \mathrm{pH} 7.5 \quad \mathrm{pH} 7.5 \quad \mathrm{pH} 7.5$
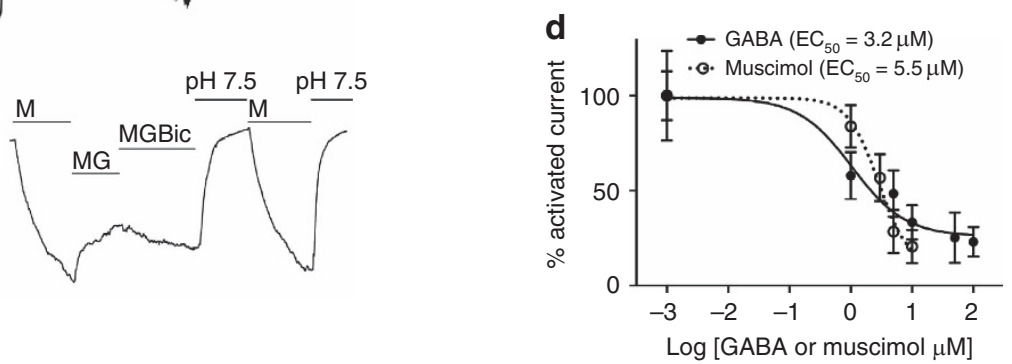

Figure 4 | TaALMT1 currents are activated by external malate at pH 7.5 and are regulated by GABA, muscimol and bicuculline. All results from $X$. laevis oocytes injected with TaALMT1 cRNA bathed at pH 7.5 and measured using two-electrode voltage-clamp electrophysiology. (a) Representative current traces at $-120 \mathrm{mV} ; \mathrm{M}=10 \mathrm{mM}$ malate; Mus $=10 \mu \mathrm{m}$ muscimol; $\mathrm{G}=100 \mu \mathrm{m} \mathrm{GABA} ; \mathrm{Bic}=100 \mu \mathrm{m}$ bicuculline from $n=5$ biological replicates for top and middle traces, $n=3$ for the bottom trace. Response of water-injected control oocytes are shown in Supplementary Fig. 6. (b,c) Current-voltage relationship of malate-activated current as regulated by muscimol and GABA as indicated applied and recorded $30 \mathrm{~s}$ after each solution change. Control-subtracted currents were normalized to the largest mean outward current at $+60 \mathrm{mV}$ ( $n=5$ independent oocytes for each treatment). (d) Concentration dependence of GABA- and muscimol-regulated inward current at $-140 \mathrm{mV}$ taken from $\mathbf{b}$ and $\mathbf{c}(n=5$ for $\mathbf{b}$, and 9 for $\mathbf{c}$ ). All data are water-control subtracted except in a. All error bars are \pm s.e.m. Experiments repeated with oocytes from at least two different frogs.

a

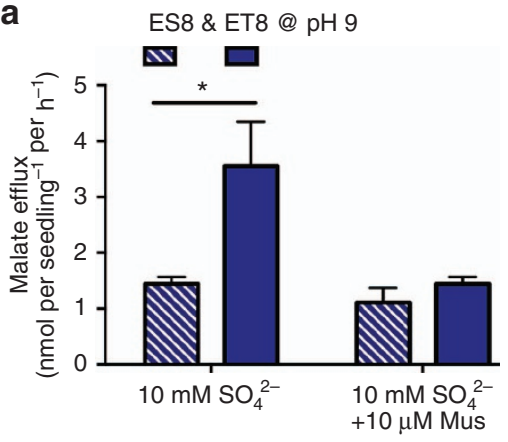

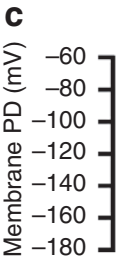

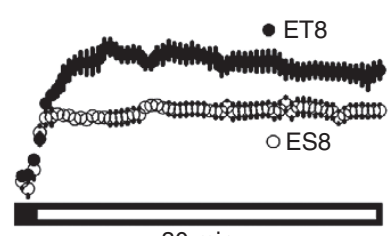

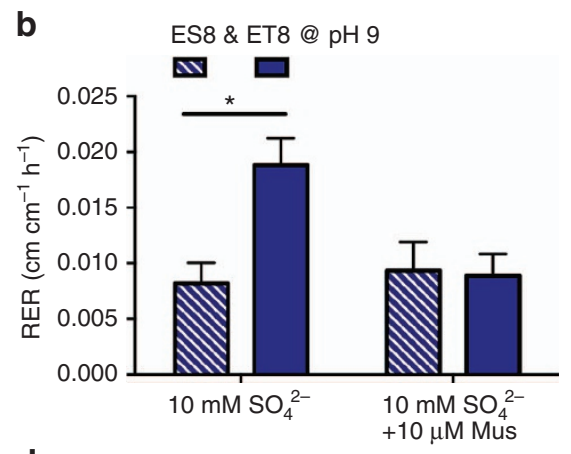

d

$30 \min$

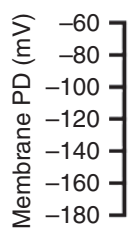

$\sum^{\infty}-180$

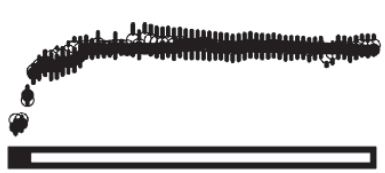

$30 \min$

Figure 5 | Muscimol-regulated anion-stimulated malate efflux at alkaline pH correlates with wheat root growth and modulates membrane potential. All experiments use ET8 and ES8 seedlings. (a) Malate efflux from, or, (b) root growth of, wheat roots after $22 \mathrm{~h}$ bathed in basal solution at pH $9+10 \mathrm{mM}$ $\mathrm{SO}_{4}^{2-} \pm 10 \mu \mathrm{M}$ muscimol (Mus). (c) Membrane potential difference (PD) across the plasma membrane of wheat root apical cells in response to $10 \mathrm{mM}$ $\mathrm{SO}_{4}^{2-}$ at $\mathrm{pH}$ 8. (d) $\mathrm{PD}$ in response to $10 \mathrm{mM} \mathrm{SO}_{4}^{2-}$ at $\mathrm{pH} 8+10 \mu \mathrm{M}$ muscimol (Mus) treatment. The Black scale bar indicates value prior to treatment and the clear bar is in presence of treatment. ${ }^{*}$ indicates significant differences between genotypes at $P<0.05$ using a one-way a two-tailed t-test (a,b). Biological replicates for $\mathbf{a}$ and $\mathbf{b}$ are $n=5$ and $\mathbf{c}$ and $\mathbf{d}$ are $n=4$. All error bars are \pm s.e.m. Controls are shown in Supplementary Fig. 8. Experiments in $\mathbf{a}$ and b are repeated at least twice.

ET8 wheat root apex fluoresces to a greater extent when exposed to the fluorescent muscimol conjugate compared with the root apex of ES8 (Fig. 7d,e). The magnitude of fluorescence therefore appears to be relative to the quantity of TaALMT1 protein present in each line, with TaALMT1 more abundant in the root apex of ET8 (refs 8,9). 


\begin{tabular}{|c|c|c|}
\hline a & $\underset{(\mu \mathrm{M})}{\mathrm{E} \mathrm{C}_{50}}$ & $\underset{(\%)}{E_{\max }}$ \\
\hline GABAA & $\approx 8.0$ & $\approx 80$ \\
\hline OsALMT5 & 1.0 & 100 \\
\hline OsALMT9 & 1.2 & 100 \\
\hline AtALMT1 & 1.3 & 66.4 \\
\hline TaALMT1 & 3.4 & 64.5 \\
\hline HvALMT1 & 0.6 & 62.0 \\
\hline VvALMT9 & 6.0 & 48.9 \\
\hline AtALMT13 & 6.8 & 40.7 \\
\hline AtALMT14 & 1.1 & 23.8 \\
\hline
\end{tabular}
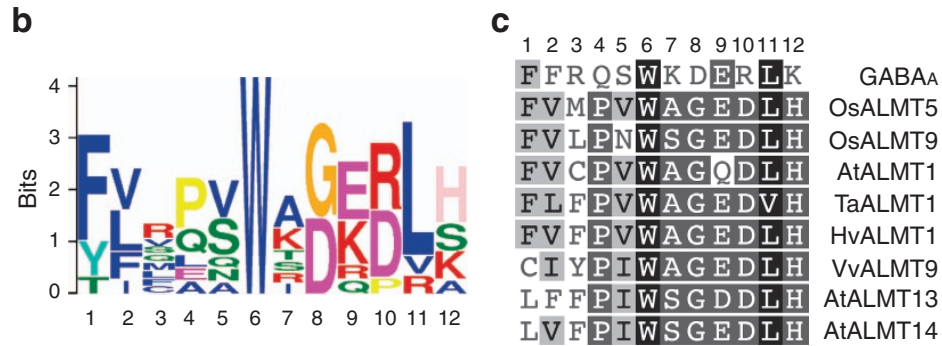

\begin{abstract}
Figure 6 | GABA regulation of transport activity is a common ALMT property as is the presence of a putative GABA-binding motif. (a) Half-maximal effective concentration $\left(\mathrm{EC}_{50}\right.$ ) and efficacy $\left(E_{\max }\right)$ of $\mathrm{GABA}$ regulation of rat $\mathrm{GABA}_{\mathrm{A}}$ receptors (average) or selected plant $\mathrm{ALMT}$ in $\mathrm{CRNA}$-injected $X$. laevis oocytes assayed using two-electrode voltage-clamp electrophysiology (Os=rice; $\mathrm{Hv}=$ barley) (full data set, Supplementary Fig. 8). (b) Sequence logo of the predicted GABA-binding motif identified using MEME analysis ${ }^{16,18}$ (detailed alignment, Supplementary Fig. 9). (c) Residues corresponding to logo in proteins from a (see Supplementary Figs 10 and 11 for this sequence and residue frequencies at each position within the motif in all other identified ALMT), identical residues shaded (black), 80\% similar (grey) and <60\% similar (unshaded). Full-sequence identifiers are AtALMT1 (AT1G08430); TaALMT1 (DQ072260); OsALMT5 (Os04g0417000); HvALMT1 (EF424084); AtALMT13 (AT5G46600); AtALMT14 (AT5G46610); OsALMT9 (Os10g0572100); VvALMT9 (XM_002275959). All measurements were carried out at least twice with different frogs.
\end{abstract}

ALMT are key transducers of GABA signalling in plants. It was previously proposed that $\mathrm{Al}^{3+}$ activation constitutes a specialized diversification of the ALMT family ${ }^{7}$; the majority of ALMT are instead suggested to underlie voltage-dependent quicklyactivating anion channel/rapidly activating (R-type) channel activity across the plasma membrane and tonoplast of most plant cell types ${ }^{7,13,14}$. R-type channels are commonly associated with cell signalling in plants in multiple cell types ${ }^{13,26}$. For instance, GABA gradients are required in female reproductive tissues to guide pollen tubes to the ovary to ensure successful fertilization ${ }^{4}$. Here, we provide evidence that GABA-regulated growth of pollen tubes ${ }^{4}$ is mediated through GABA-gated ALMT, as muscimol reduced pollen tube growth and this growth reduction was attenuated by bicuculline (Fig. 8).

\section{Discussion}

Our findings in wheat roots suggest that GABA negatively regulates the activity of TaALMT1 - a protein that is constitutively present in root apical cells ${ }^{8,9}$ - to prevent malate efflux from roots under certain conditions. This occurs under acidic conditions (for example, Fig. 1), and is likely to occur under a range of other stresses that increase GABA concentration in plant tissues such as cold, salt or heat ${ }^{1,2}$. Excessive carbon efflux would be a disadvantage when conservation of valuable plant reserves of reduced carbon and energy was required, as this would be essential for continued growth and stress tolerance. We also discovered that malate was excreted from wheat roots through TaALMT1 at alkaline $\mathrm{pH}$, with greater malate efflux linked to greater root growth. While TaALMT1 is commonly associated with aluminium tolerance in acid soils, it was recently found that bread wheat genotypes with TaALMT1 also have higher yields in alkaline soils $\mathrm{s}^{27,28}$. The excretion of malate at high $\mathrm{pH}$, probably coupled to the efflux of protons would tend to buffer the cell wall space to a lower and more conducive $\mathrm{pH}$ for the cell wall loosening that is required for root extension, and for nutrient uptake. Therefore, malic acid efflux would be advantageous in alkaline soils. The observation that GABA tightly regulates root ALMT activity therefore has implications for how plants regulate $\mathrm{C}$ sequestration into the rhizosphere, a major energy source for the soil microbiome, and how this might be affected by stress.

GABA and the enzymes that regulate the GABA shunt pathway play a key role in primary $\mathrm{C} / \mathrm{N}$ metabolism by modulating the flux of carbon and energy through the TCA cycle $^{29}$. The discovery of anion channels in plants gated by physiologically relevant GABA concentrations ${ }^{2}$ links plant metabolism with signalling under both stressed and nonstressed conditions. This is a conceptual advance that opens novel research avenues for crop improvement, particularly for altering stress tolerance, as GABA increases rapidly during multiple stresses ${ }^{2}$. ALMT form a multigenic protein family with different members having diverse expression throughout plant tissues. The concentrations of anions required to activate ALMT are commonly encountered within plant tissue, suggesting that ALMT are ordinarily active in cells or are at least primed for activation. This is consistent with the many physiological roles that are emerging for ALMT encompassing stress tolerance, mineral nutrition, vacuolar malate accumulation and stomatal aperture control ${ }^{8,13-15}$. As ALMT activity, or the inhibition of their activity, can directly affect membrane potential with downstream physiological responses ${ }^{13}$ (Fig. 5c,d), it is likely that the different family members more broadly transduce GABA effects throughout plant tissues.

Our results invoke interesting questions regarding the evolution of amino-acid signalling across kingdoms. GABA exerts its inhibitory effect in mature brain neurones by activation of $\mathrm{Cl}^{-}$ currents through $\mathrm{GABA}_{\mathrm{A}}$ receptor channels. This tends to hyperpolarize the membrane potential and inhibits excitability. In plants the anion equilibrium potential is normally very positive so that when ALMT proteins are activated there is a depolarization (that is, Fig. 5c). Plant action potentials are largely based on activation of voltage-dependent anion channels ${ }^{30}$. Thus GABA inhibition of ALMT will tend to hyperpolarize the membrane potential and decrease excitability, similar to the effect of GABA in animal neurones. However, despite having a similar effect on membrane potential, the proteins that transduce GABA signals in plants and animals are not orthologues. They contain no extensive regions of sequence homology, but contain a small region that shares significant similarity to a region that has been previously associated with GABA interaction in mammalian $\mathrm{GABA}_{\mathrm{A}}$ receptors ${ }^{16,17}$ (Fig. 6). The association of muscimolBODIPY fluorescence with membranes that contain a significant GABA-responsive ALMT protein in planta and heterologous systems, and not with membranes containing a site-directed ALMT mutant with diminished GABA sensitivity (Fig. 7), suggests that GABA may interact directly with this similar motif in ALMT and $\mathrm{GABA}_{\mathrm{A}}$ receptors. However, like in $\mathrm{GABA}_{\mathrm{A}}$ receptors it is highly likely that other parts of the protein, either of the monomer or between interacting monomers in a multimeric form, constitute the binding region. Interacting regions with the region we have identified will be the subject of future research. It is unclear whether the existence of a similar GABA-binding motif 
a

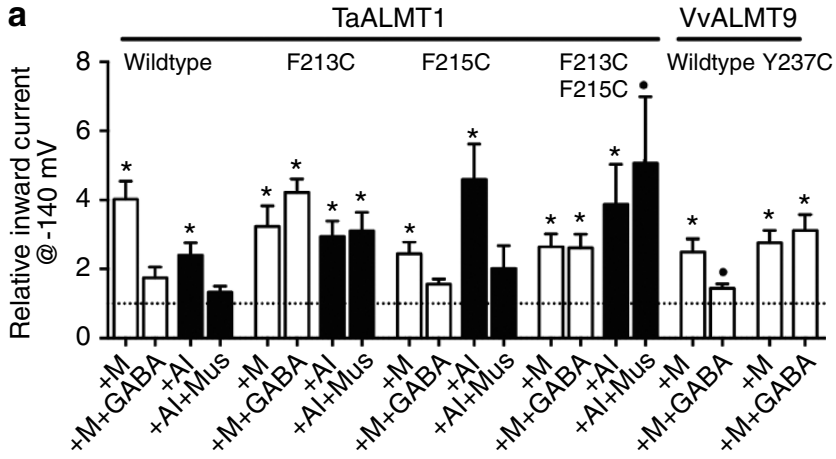

b
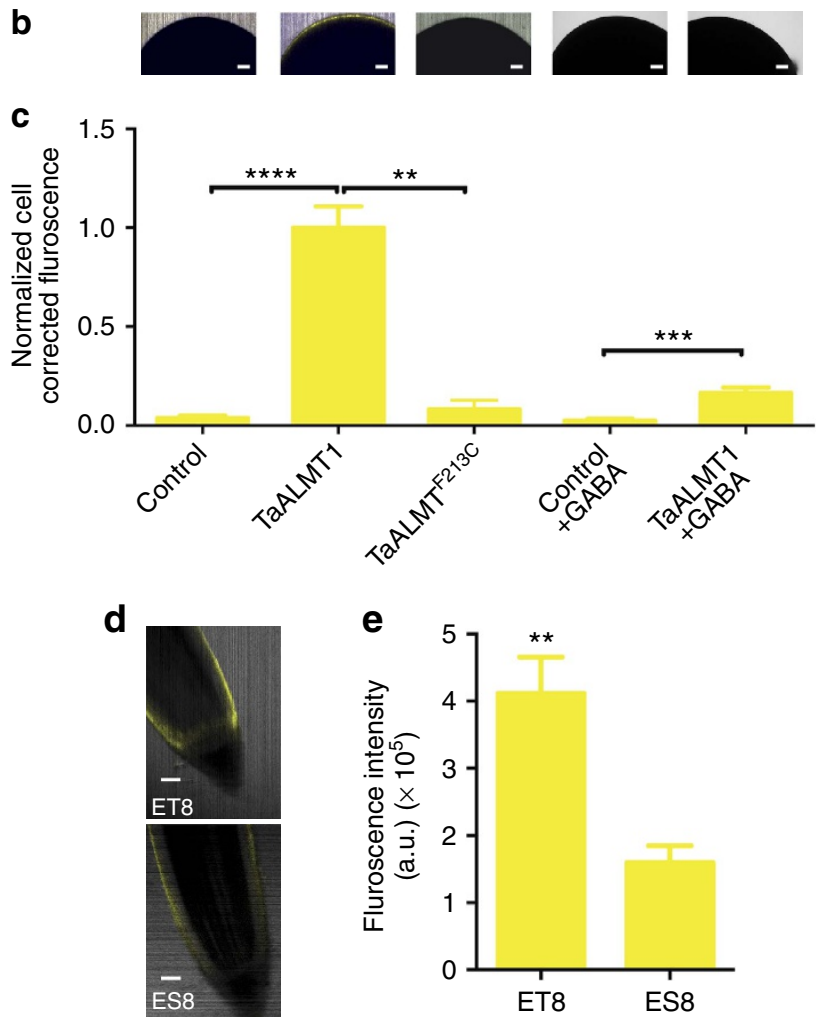

Figure 7 | GABA regulation of ALMT transport activity is dependent on an aromatic residue within the predicted GABA-binding motif.

(a) Sensitivity of wild-type and site-directed ALMT mutants ( $M, 10 \mathrm{mM}$ malate; GABA, $100 \mu \mathrm{M}$ ), at pH 4.5 ( $\mathrm{Al}, 100 \mu \mathrm{M}$; muscimol (Mus), $10 \mu \mathrm{M}$ ) assayed by two-electrode voltage-clamp electrophysiology in cRNA-injected $X$. laevis oocytes. Currents were normalized to $-140 \mathrm{mV}$ value in basal solution (at each $\mathrm{pH}$ ) for each protein (dotted line). For all treatments, $n=3$ for TaALMT1,

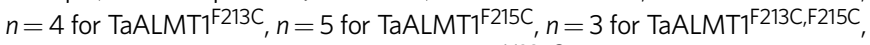
$n=7$ for VvALMT9 and $n=4$ for VvALMT9Y237C. *indicates significant differences from basal currents within each treatment $(P<0.05)$, • indicates a significance difference between activated currents $(P<0.05)$, using a onesample $t$-test on log-transformed data. $(\mathbf{b}, \mathbf{c})$ Fluorescence of the plasma membrane of $X$. laevis oocytes after exposure to the muscimol-BODIPY conjugate, control (water injected) $(n=12)$, TaALMT1- $(n=14)$, TaALMTF $^{\mathrm{F} 213 \mathrm{C}}$. injected $(n=8)$ and oocytes co-incubated with GABA and muscimol-BODIPY, control (water injected) $(n=4)$ and TaALMT1-injected $(n=6)$. (d,e)

Fluorescence of wheat roots after exposure to the muscimol-BODIPY conjugate $\left(n=5\right.$ for each). ${ }^{\star \star},{ }^{\star \star \star}$ and ${ }^{\star \star \star \star}$ indicates significant differences in fluorescence between control, TaALMT1 and TaALMT1 ${ }^{\mathrm{F} 213 \mathrm{C}}$ at $P<0.01,0.001,0.0001$, respectively, using one-way analysis of variance and Tukey's post hoc test. All error bars are \pm s.e.m., scale bars, $100 \mu \mathrm{m}$. Experiments in a were carried out at least twice with two different frogs. (b,c) Measurements were repeated thrice with three different frogs. (d,e) Fluorescence measurements were carried out twice on roots in different experiments.
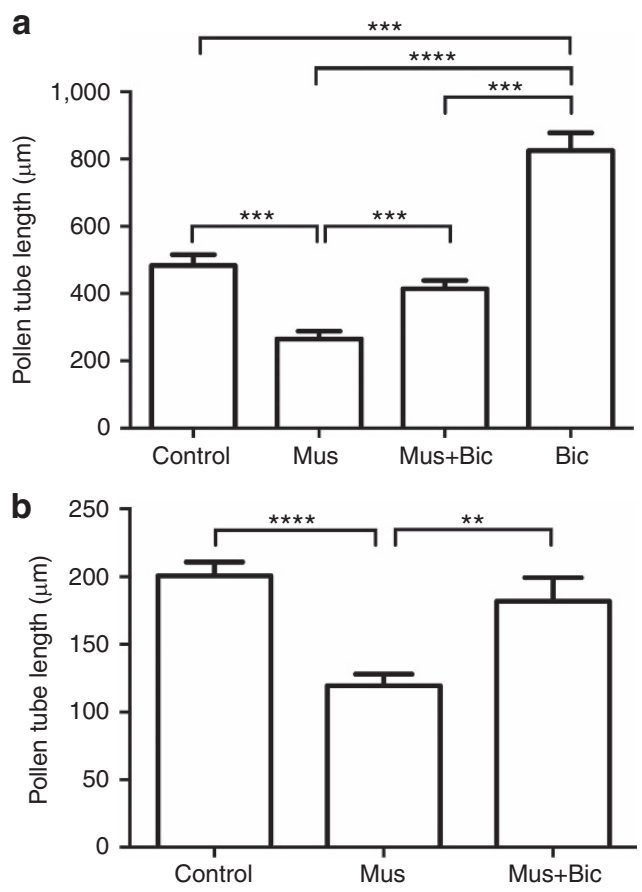

Figure 8 | Muscimol reduces Arabidopsis thaliana and Vitis vinifera pollen tube elongation in vitro, and bicuculline antagonizes muscimol regulation.

(a) In vitro Arabidopsis pollen tube elongation after $3 \mathrm{~h} \pm$ treatments $(n=499)$. Mus ( $20 \mu \mathrm{M}$ muscimol and Bic $(200 \mu \mathrm{M}$ bicuculline). (b) In vitro grapevine pollen tube elongation after $6 \mathrm{~h} \pm$ treatments, mean $\Delta$ from control mean \pm s.e.m. $(12.5 \pm 0.16 \mathrm{~mm})(n=157-193$ per treatment). **, , and ${ }^{\star \star \star \star}$ indicate significant differences between genotypes at $P<0.01$, 0.001 and 0.0001 , respectively, using a one-way analysis of variance and Tukey's post hoc test. All error bars are \pm s.e.m. (b) The experiments were replicated at least three times.

in multiple kingdoms is an example of convergent evolution or the recruitment of an ancestral GABA motif into distinct proteins. Exploration of these possibilities would form an interesting area of future study, as would the employment of methods with increased sensitivity for assessing the variation in GABA-binding affinity among ALMT using direct binding assays or the substituted-cysteine accessibility method ${ }^{19}$.

It is also interesting to note that compounds derived from plants (bicuculline) or mycorrhizal fungi (musicmol), that are known to regulate mammalian GABA receptors, can affect ion transport in plants, and as a consequence plant growth. In light of this, it would seem sensible to reassess the roles of these and similar compounds in nature. Furthermore, since plants, animals and fungi respond to GABA, it has been suggested that GABA can facilitate communication between kingdoms ${ }^{31}$. Our data endorse ALMT as prime candidates to mediate GABA-based signalling in plants.

\section{Methods}

Chemicals. All chemicals were supplied by Sigma, except muscimol and muscimol-BODIPY TMR-X conjugate ${ }^{23}$ supplied by Life Technologies. Bicuculline is unstable at alkaline $\mathrm{pH}^{32}$, so its effects were tested over long time courses only at acidic $\mathrm{pH}(>1 \mathrm{~h})$, not under alkaline conditions.

Preparation of ALMT and site-directed mutants. ALMT were cloned and mutagenized using primers listed in Supplementary Table 1.The coding nucleotide sequence for various ALMT (AB081803.1 (TaALMT1); EF424084 (HvALMT1); AL606598 (OsALMT5); AAL86482 (OsALMT9); NM_124030 (AtALMT13); NM_124031 (AtALMT14); XM_002275959.1 (VvALMT9)) were cloned using primers listed in Supplementary Table 1 from complementary DNA made from 
RNA extracted from the target plant into pGEMHE-DEST (GATEWAY enabled $)^{33}$. TaALMT1 and VVALMT9 in pGEMHE-DEST were used as a template for mutagenesis. Primers listed in Supplementary Table 1 were designed based on the QuikChange Site Directed Mutagenesis Kit PCR protocol (Stratagene). The amplified mutagenized products were transformed into Escherichia coli and confirmed through sequencing. Plasmid DNA was extracted using the Mini Prep kit from Sigma, and $1 \mu \mathrm{g}$ of plasmid DNA was linearized with the restriction enzyme Nhel except for $V v A L M T 9$, which was linearized using Sph1. Capped complementary RNA (cRNA) was synthesized using the mMESSAGE Mmachine T7 Kit (Ambion) as per the manufacturer's instructions.

Voltage-clamp electrophysiology and confocal microscopy. Electrophysiology was performed on $X$. laevis oocytes 2 days post injection with water/cRNA ${ }^{24,33}$. Oocytes were injected with $46 \mathrm{nl}$ of RNase-free water using a micro-injector (Nanoject II, automatic nanolitre injector, Drummond Scientific) $\pm 16-32 \mathrm{ng}$ cRNA. Sodium malate $(10 \mathrm{mM}, \mathrm{pH} 7.5)$ was injected into oocytes $1 \mathrm{~h}$ before measurement. Basal external solutions for anion activation contained $0.7 \mathrm{mM}$ $\mathrm{CaCl}_{2}$ and mannitol to $220 \mathrm{mOsm} \mathrm{kg}^{-1}, \pm 10 \mathrm{mM}$ malic acid and other treatments outlined in the figure legends, buffered with $5 \mathrm{mM}$ BTP/MES from $\mathrm{pH} 4.5$ to 9.0. Aluminium activation was carried out in ND88 (ref. 15). All data are subtracted from mean currents from water-injected controls, except where stated. For confocal imaging, X. laevis oocytes or wheat roots were incubated in basal external solution ( $\mathrm{pH}$ 7.5) with the addition of $10 \mu \mathrm{M}$ muscimol-BODIPY TMR-X conjugate $^{23}$ for $10 \mathrm{~min}, 2$ days post injection, then washed in basal solution for 7 min and visualized under a Zeiss Confocal microscope with Pascal LSM 5 software with excitation at $514 \mathrm{~nm}$ and emission at $>530 \mathrm{~nm}$. The images were analysed with LSM 5 image examiner (Zeiss). Fluorescence was quantified using the ImageJ software $(\mathrm{NIH})^{34}$. In all X. laevis oocyte experiments, solutions were applied to gene-injected oocytes in the same order as controls (water injected). Randomly selected oocytes were alternated between control and gene injected to limit any bias caused by time-dependent changes after gene injection or malate injection. The University of Adelaide Animal Ethics Committee approved the Xenopus laevis oocyte experiments; project number S-2009-044B.

Root assays. NILs of wheat ET8 and ES8 (ref. 8), and barley ${ }^{10}$ were surface sterilized, and 4-day-old seedlings were placed in a microcentrifuge tube with roots immersed for $22 \mathrm{~h}$ in $3 \mathrm{mM} \mathrm{CaCl}_{2}, 5 \mathrm{mM} \mathrm{MES} / \mathrm{BTP}$ to $\mathrm{pH} 4.5-9.0 \pm$ treatments, with total root length and number measured at 0 and $22 \mathrm{~h}$. For root flux assays and growth measurement, experiments were carried out wherein the identity of the treatment solutions was unknown to the person performing the experiments to remove any bias. Malate concentrations were measured on an OMEGA plate-reading spectrophotometer (BMG) following the K-LMALR/K-LMALL assay ${ }^{11}$ (Megazyme). One hundred microlitre of the treatment solution collected from roots, or after centrifugation of BY2 samples at $500 \mathrm{~g}$ in a desktop microcentrifuge, was added to a mastermix containing the various components of the K-LMALR/K-LMALL assay $^{11}$ (Megazyme) kit as per the manufacturer's instructions. The change in absorbance at $340 \mathrm{~nm}$ was used to calculate the concentration of malate in the samples. GABA concentrations were measured, also on the OMEGA plate-reading spectrophotometer, following the GABase enzyme assay ${ }^{35}$. Briefly, $5 \mathrm{~mm}$ of root tips were excised and snap frozen in liquid nitrogen after seedlings were subjected to treatment solutions for $22 \mathrm{~h}$. The root tips were ground in liquid nitrogen and known weight was added to methanol and incubated at $25^{\circ} \mathrm{C}$ for $10 \mathrm{~min}$. The samples were vacuum dried, resuspended in $70 \mathrm{mM} \mathrm{LaCl}_{3}$, pelleted at $500 \mathrm{~g}$ in a desktop microcentrifuge and precipitated with $1 \mathrm{M} \mathrm{KOH}$. These samples were recentrifuged at $500 \mathrm{~g}$ and $90.34 \mu \mathrm{l}$ of supernatant was assayed for GABA concentrations using the GABase enzyme from Sigma as per the manufacturer's instructions. Membrane potential measurements were carried out with seedlings placed horizontally in a custom chamber ${ }^{36}$. Plants were allowed to stabilize in the above solution (without treatments) for $60 \mathrm{~min}$ prior to measurement. Measurements were made $1 \mathrm{~mm}$ from the meristem in the elongation zone. Fine-tipped borosilicate glass microelectrodes (Clark Electromedical Instruments) were filled with $1 \mathrm{M} \mathrm{KCl}$ and connected to a Microelectrode Ion Flux Estimation (MIFE) amplifier ${ }^{36}$ via a $\mathrm{Ag}-\mathrm{AgCl}$ half-cell and inserted into the root tissue with a manually operated micromanipulator (Narishige). Voltage recordings were made on the MIFE CHART software ${ }^{36}$.

Tobacco BY2 malate efflux. Tobacco suspension cells (Nicotiana tabacum L. cv. Samsun, a cell line SL) transformed with the TaALMT1 gene from wheat (cell line 4) or an empty vector (cell line 9), originally generated by Takayuki Sasaki at Okayama University ${ }^{11}$, were grown in Murashige and Skoog's medium on a rotary shaker ( $\sim 100$ r.p.m.) until the logarithmic phase. Aliquots of suspension cells containing $\sim 1$ g of cells were centrifuged and gently resuspended in a basal BY2 solution ${ }^{11}$. TaALMT1-expressing or vector-control tobacco-BY2 suspension cells $(0.15 \mathrm{~g})$ were placed in $3 \mathrm{ml}$ of $3 \mathrm{mM} \mathrm{CaCl}_{2}, 3 \mathrm{mM}$ sucrose and $5 \mathrm{mM}$ MES/ BTP to $\mathrm{pH} 4.5-9.0 \pm$ treatments in $50 \mathrm{ml}$ tubes on a rotary shaker for $22 \mathrm{~h}$, unless otherwise stated. Malate fluxes were measured as stated above.

Pollen tube experiments. Pollen tube assays were followed ${ }^{4}$ with modification. Pollen was harvested from Vitis Vinifera cv. Shiraz (clone BVRC17) grapevine cuttings ${ }^{37}$ with 50 flowers (10 flowers from 5 plants) harvested on the day of anthesis and fixed in liquid $\mathrm{N}_{2}$ for storage at $-80^{\circ} \mathrm{C}$ before use. Pollen was transferred using a fine brush onto cavity slides containing $1 \mathrm{ml}$ of pollen in modified germination medium ${ }^{38}$ containing $15 \%$ sucrose, $1.27 \mathrm{mM}$

$\mathrm{Ca}\left(\mathrm{NO}_{3}\right)_{2} .4 \mathrm{H}_{2} \mathrm{O}, 1 \mathrm{mM} \mathrm{KNO}_{3}, 0.81 \mathrm{mM} \mathrm{MgSO}_{4} .7 \mathrm{H}_{2} \mathrm{O}$ and $1.6 \mathrm{mM} \mathrm{H}_{3} \mathrm{BO}_{3}$, made in $1 \mathrm{mM}$ MES and buffered to $\mathrm{pH} 5.6$ using $1 \mathrm{M}$ TRIS) and allowed to germinate at $25^{\circ} \mathrm{C}$ within $1 \mathrm{~h}$ of thawing. The slides were placed in Petri plates containing moistened tissue paper and sealed with parafilm to ensure humidity in the Petri plates. Arabidopsis thaliana ecotype Col-0 were grown in hydroponically ${ }^{39}$. Pollen grains from open flowers WT Col-0 were suspended on modified Arabidopsis pollen germination medium ${ }^{40}$ containing the basic components $(0.01 \%$ boric acid, $5 \mathrm{mM}$ $\mathrm{CaCl}_{2}, 5 \mathrm{mM} \mathrm{KCl}, 1 \mathrm{mM} \mathrm{MgSO}_{4}, 250 \mu \mathrm{M}$ HEPES, $10 \%$ sucrose and $\mathrm{pH}$ 7.5-7.8), and incubated at $22{ }^{\circ} \mathrm{C}$. Pollen germination medium (final volume $20 \mathrm{ml}$ ) was always prepared fresh from $100 \times$ stock solutions of the main components using autoclaved MilliQ water (Millipore). Multiple representative images of the entire pollen population were taken under a ZEISS Axiophot microscope with a TOUPCAM UCMOS05100KPA camera and ToupView software (ToupTek). All pollen tube lengths were quantified with ImageJ software (NIH).

Statistics. All graphs and statistics were performed in Graphpad Prism 6. All data shown are mean \pm s.e.m. Asterisks indicate significance between values as determined by one-way analysis of variance with Tukey's post hoc test, unless otherwise stated.

\section{References}

1. Bouche, N. \& Fromm, H. GABA in plants: just a metabolite? Trends Plant Sci. 9, 110-115 (2004).

2. Kinnersley, A. M. \& Turano, F. J. Gamma aminobutyric acid (GABA) and plant responses to stress. Crit. Rev. Plant Sci. 19, 479-509 (2000).

3. Renault, H. et al. $\gamma$-Aminobutyric acid transaminase deficiency impairs central carbon metabolism and leads to cell wall defects during salt stress in Arabidopsis. Plant Cell Environ. 36, 1009-1018 (2013).

4. Palanivelu, R., Brass, L., Edlund, A. F. \& Preuss, D. Pollen tube growth and guidance is regulated by $P O P 2$, an Arabidopsis gene that controls GABA levels. Cell 114, 47-59 (2003).

5. Olsen, R. W. \& Sieghart, W. International Union of Pharmacology LXX.

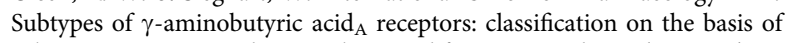
subunit composition, pharmacology, and function. Update. Pharmacol. Rev. 60, 243-260 (2008).

6. Batushansky, A. et al. Combined transcriptomics and metabolomics of Arabidopsis thaliana seedlings exposed to exogenous GABA suggest its role in plants is predominantly metabolic. Mol. Plant 7, 1065-1068 (2014).

7. Dreyer, I., Gomez-Porras, J. L., Riaño-Pachón, D. M., Hedrich, R. \& Geiger, D. Molecular evolution of slow and quick anion channels (SLACs and QUACs/ ALMTs). Front. Plant Sci. 3, 263 (2012).

8. Sasaki, T. et al. A wheat gene encoding an aluminum-activated malate transporter. Plant J. 37, 645-653 (2004).

9. Ryan, P. R. et al. The multiple origins of aluminium resistance in hexaploid wheat include Aegilops tauschii and more recent cis mutations to TaALMT1. Plant J. 64, 446-455 (2010).

10. Delhaize, E. et al. Engineering high-level aluminium tolerance in barley with the ALMT1 gene. Proc. Natl Acad. Sci. USA 101, 15249-15254 (2004).

11. Zhang, W. H. et al. Characterization of the TaALMT1 protein as an $\mathrm{Al}^{3+}$. activated anion channel in transformed tobacco (Nicotiana tabacum L.) cells. Plant Cell Physiol. 49, 1316-1330 (2008).

12. Li, R., Raikhel, N. V. \& Hicks, G. R. in Endocytosis in Plants 37-61 (Springer, 2012).

13. Meyer, S. et al. ALMT12 represents an R-type anion channel required for stomatal movements in Arabidopsis guard cells. Plant J. 63, 1054-1062 (2010).

14. De Angeli, A., Zhang, J., Meyer, S. \& Martinoia, E. AtALMT9 is a malateactivated vacuolar chloride channel required for stomatal opening in Arabidopsis. Nat. Commun. 4, 1804 (2013).

15. Hoekenga, O. A. et al. AtALMT1, which encodes a malate transporter, is identified as one of several genes critical for aluminium tolerance in Arabidopsis. Proc. Natl Acad. Sci. USA 103, 9738-9743 (2006).

16. Bergmann, R., Kongsbak, K., Sørensen, P. L., Sander, T. \& Balle, T. A unified model of the $\mathrm{GABA}_{\mathrm{A}}$ receptor comprising agonist and benzodiazepine binding sites. PLoS ONE 8, e52323 (2013).

17. Miller, P. S. \& Aricescu, A. R. Crystal structure of a human $\mathrm{GABA}_{\mathrm{A}}$ receptor. Nature 512, 270-275 (2014).

18. Bailey, T. L., Williams, N., Misleh, C. \& Li, W. W. MEME: discovering and analyzing DNA and protein sequence motifs. Nucleic Acids Res. 34, W369-W373 (2009).

19. Boileau, A. J., Evers, A. R., Davis, A. F. \& Czajkowski, C. Mapping the agonist binding site of the $\mathrm{GABA}_{\mathrm{A}}$ receptor: evidence for a beta-strand. J. Neurosci. 19, 4847-4854 (1999).

20. Sedelnikova, A. et al. Mapping the $\operatorname{rho}(1) \operatorname{GABA}(C)$ receptor agonist binding pocket-constructing a complete model. J. Biol. Chem. 280, 1535-1542 (2005). 
21. Lummis, S. C. R., L Beene, D., Harrison, N. J., Lester, H. A. \& Dougherty, D. A. A cation- $\pi$ binding interactions with a tyrosine binding site of the $G_{A B A}$ receptor. Chem. Biol. 12, 993-997 (2005).

22. Motoda, H. et al. The membrane topology of ALMT1, an aluminum-activated malate transport protein in wheat (Triticum aestivum). Plant Signal. Behav. 2, 467-472 (2007).

23. $\mathrm{Vu}, \mathrm{T}$. Q. et al. Activation of membrane receptors by a neurotransmitterreceptor conjugate designed for surface attachment. Biomaterials 26, 1895-1903 (2005).

24. Ligaba, A. et al. Functional, structural and phylogenetic analysis of domains underlying the $\mathrm{Al}$ sensitivity of the aluminium-activated malate/anion transporter, TaALMT1. Plant J. 76, 766-780 (2013).

25. Furuichi, T. et al. An extracellular hydrophilic carboxy-terminal domain regulates the activity of TaALMT1, the aluminum-activated malate transport protein of wheat. Plant J. 64, 47-55 (2010).

26. Guttermuth, T. et al. Pollen tube growth regulation by free anions depends on the interaction between the anion channel SLAH4 and calcium-dependent protein kinases CPK2 and CPK20. Plant Cell 25, 4525-4543 (2013).

27. McDonald, G. K., Taylor, J. D., Verbyla, A. \& Kuchel, H. Assessing the importance of subsoil constraints to yield of wheat and its implications for yield improvement. Crop Pasture Sci. 63, 1043-1065 (2013).

28. Eagles, H. A. et al. Ppd1, Vrn1, ALMT1 and Rht genes and their effects on grain yield in lower rainfall environments in southern Australia. Crop Pasture Sci. 65, 159-170 (2014).

29. Fait, A., Fromm, H., Walter., D., Galili, G. \& Fernie, A. R. Highway or byway: the metabolic role of the GABA shunt in plants. Trends Plant Sci. 13, 14-19 (2008).

30. Tyerman, S. D. Anion channels in plants. Annu. Rev. Plant Physiol. Plant Mol. Biol. 43, 351-373 (1992).

31. Shelp, B. J., Bown, A. W. \& Faure, D. Extracellular $\gamma$-aminobutyrate mediates communication between plants and other organisms. Plant Physiol. 142, 1350-1352 (2006).

32. Pong, S. F. \& Graham, Jr. L. T. A simple preparation method of bicuculline methiodide, a water-soluble GABA antagonist. Brain Res. 58, 266-267 (1973).

33. Preuss, C. P., Huang, C. Y., Gilliham, M. \& Tyerman, S. D. Channel-like characteristics of the low-affinity barley phosphate transporter PHT1;6 when expressed in Xenopus oocytes. Plant Physiol. 152, 1431-1441 (2011).

34. Burgess, A. et al. Loss of human Greatwall results in G2 arrest and multiple mitotic defects due to deregulation of the cyclin B-Cdc2/PP2A balance. Proc. Natl Acad. Sci. USA 107, 12564-12569 (2010).

35. Zhang, G. \& Bown, A. W. The rapid determination of $\gamma$-aminobutyric acid. Phvtochemistry 44, 1007-1009 (1997).

36. Wherrett, T., Ryan, P. R., Delhaize, E. \& Shabala, S. Effect of aluminium on membrane potential and ion fluxes at the apices of wheat roots. Funct. Plant Biol. 32, 199-208.

37. Baby, T., Hocking, B., Gilliham, M., Tyerman, S. D. \& Collins, C. Modified method for producing grapevine plants in controlled environments. Am. J. Enol. Vitic. 65, 261-267 (2014).

38. Brewbaker, J. L. \& Kwack, B. H. The essential role of calcium ion in pollen germination and pollen tube growth. Am. J. Bot. 50, 859-865 (1963).
39. Conn, S. J. et al. Protocol: A simple and versatile hydroponics growth system for nutritional and physiological analysis of Arabidopsis thaliana and other plants. Plant Methods 9, 4 (2013).

40. Boavida, L. C. \& McCormick, S. Temperature as a determinant for increased and reproducible in vitro pollen germination in Arabidopsis thaliana. Plant J. 52, 570-582 (2007).

\section{Acknowledgements}

We thank Wendy Sullivan for harvesting oocytes, tobacco cell preparation and technical assistance, and Asmini Athman and Muhammad Kamran for help with plant experiments. We thank Muyun Xu for cloning the cDNAs of OsALMT5 and OsALMT9. We thank Roger Leigh, Barry Shelp, Tony Ashton, Geoff Fincher and Manny Delhaize for critical reading of the manuscript. The Australian Research Council and Waite Research Institute, University of Adelaide have supported this research by funding M.G. (FT130100709), M.G. S.D.T and P.R.R. through DP130104205, and M.G. and S.D.T through CE140100008. J.A.F. acknowledges Fundação para a Ciência e Tecnologia (PTDC/BEX-BCM/0376/2012 and PTDC/BIA-PLA/4018/ 2012) and the University of Maryland. P.D. acknowledges an FCT Fellowship (SFRH/BD/69168/2010).

\section{Author contributions}

M.G. and S.D.T. conceived the project, supervised the research and wrote the manuscript. M.G., S.D.T. and S.A.R. planned and designed experiments. S.A.R. performed cloning, oocyte, tobacco and wheat experiments; analysed data and drafted sections of the manuscript. S.D.T. and M.G. performed additional oocyte experiments and data analysis. P.R.R. performed additional wheat root flux experiments. S.S. contributed to experimental design and data interpretation of membrane potentials, and J.B. performed membrane potential measurements. V.C. cloned additional genes, B.X. performed additional oocyte, plant and tobacco experiments, S.U. and S.K. designed and performed grapevine pollen tube experiments and J.A.F. and P.D. designed and performed the Arabidopsis pollen tube experiments. S.W. performed additional growth assays. All authors had intellectual input into the project and commented on the manuscript.

\section{Additional information}

Supplementary Information accompanies this paper at http://www.nature.com/ naturecommunications

Competing financial interests: The authors declare no competing financial interests.

Reprints and permission information is available online at http://npg.nature.com/ reprintsandpermissions/

How to cite this article: Ramesh, S. A. et al. GABA signalling modulates plant growth by directly regulating the activity of plant-specific anion transporters. Nat. Commun. 6:7879 doi: $10.1038 /$ ncomms8879 (2015)

This work is licensed under a Creative Commons Attribution 4.0 International License. The images or other third party material in this article are included in the article's Creative Commons license, unless indicated otherwise in the credit line; if the material is not included under the Creative Commons license, users will need to obtain permission from the license holder to reproduce the material. To view a copy of this license, visit http://creativecommons.org/licenses/by/4.0/ 


\section{Corrigendum: GABA signalling modulates plant growth by directly regulating the activity of plant-specific anion transporters}

Sunita A. Ramesh, Stephen D. Tyerman, Bo Xu, Jayakumar Bose, Satwinder Kaur, Vanessa Conn,

Patricia Domingos, Sana Ullah, Stefanie Wege, Sergey Shabala, José A. Feijó, Peter R. Ryan \& Matthew Gilliham

Nature Communications 6:7879 doi: 10.1038/ncomms8879 (2015); Published 29 Jul 2015; Updated 28 Aug 2015

The original version of this Article contained a typographical error in the spelling of the author Matthew Gilliham, which was incorrectly given as Matthew Gillham. This has now been corrected in both the PDF and HTML versions of the Article.

(c) This work is licensed under a Creative Commons Attribution 4.0 International License. The images or other third party material in this article are included in the
article's Creative Commons license, unless indicated otherwise in the credit line; if the material is not included under the Creative Commons license, users will need to obtain permission from the license holder to reproduce the material. To view a copy of this license, visit http://creativecommons.org/licenses/by/4.0/ 